\title{
LA SIMETRÍA DE LA RELACIÓN ADJETIVA CIVIL Y EL ABUSO PROCESAL DE LOS JUECES
}

["The Symmetry of the Civil Procedural Relationship and the Judge's Abuse of Process"]

\author{
Francesco Carretta Muñoz* \\ Pontificia Universidad Católica de Valparaíso, Chile
}

\begin{abstract}
RESUMEN
Se examinan las conductas judiciales que infringen el principio de la buena fe procesal y los posibles remedios que ofrece el ordenamiento procesal chileno. Como fundamento general se expone la necesidad de establecer una relación adjetiva de carácter simétrico.

\section{Palabras clave}

Dolo procesal - Abuso procesal - Dolo procesal de los jueces - Abuso procesal de los jueces.
\end{abstract}

\begin{abstract}
This work analyzes the judicial conduct breaching the principle of procedural good faith and the likely remedies that the Chilean legal system offers. As general grounds, the need of establishing a procedural relationship of a symmetric nature is set forth.

\section{KEYWORDS}

Procedural fraud - Procedural abuse - Judge's procedural fraud - Judge's procedural abuse.
\end{abstract}

ReCibido el 18 de abril y ACEPTADo el 4 de junio de 2012.

* Abogado, doctor en Derecho por la Pontificia Universidad Católica de Valparaíso. Profesor agregado de la Facultad de Derecho de la Pontificia Universidad Católica de Valparaíso. Juez del tribunal de familia de Valparaíso. Dirección postal: Facultad de Derecho, Pontificia Universidad Católica de Valparaíso, Casilla 4055, Valparaíso, Chile. Correo electrónico: fcarretta@me.com. 


\section{Planteamiento}

En la doctrina no se menciona comúnmente la posibilidad de que sea el juez quien pueda cometer abuso procesal ${ }^{1}$. Ello puede deberse a dos factores: a que el abuso judicial se sobrentienda en todo discurso sobre la buena o mala fe de la relación procesal ${ }^{2}$; o bien a que se crea que el juez y las partes actúan en un plano diverso en el desarrollo del proceso y han de aplicárseles estatutos diferenciados. En el primer caso no existe justificación suficiente para dejar de tratar la problemática expresamente. El tema tiene ciertas aristas y si bien las conductas abusivas de todos los integrantes de la relación son lo mismo en sustancia, en tanto todos defraudan los fines del proceso con actitudes de ese tipo, hay algunas diferencias que merecen otorgarle un estatuto diferenciado a unos y otros. Además, pasar por alto la cuestión concerniente a los magistrados podría inducir a pensar que este tópico carece de vigencia, importancia o que, derechamente, no le resulta aplicable al juez. Por el contrario, su referencia expresa deja de manifiesto la utilidad del tema, con miras a un tratamiento más específico y expreso que el actual. El segundo factor, que desconoce la aplicación del principio de moralidad procesal a la magistratura, no se condice con una visión colaborativa del proceso que según se examinará, tiene como causas, entre otras, la perdida del carácter dialéctico del proceso y la escasa comprensión del significado de la imparcialidad del juzgador dentro del pleito.

En el presente estudio se pretenden exponer las causas citadas, para sostener que existe un cierto plano de igualdad (reciprocidad) en el desarrollo de los imperativos exigibles a todos los intervinientes de un proceso civil. Desde esa base se sostendrá que no hay razón suficiente para no reprocharle al juez abuso procesal, tal como éste está habilitado para hacerlo respecto a las partes. Luego se expondrán las formas como se recoge esta situación en la legislación y los remedios disponibles en el derecho vigente. Se tomará como

${ }^{1}$ En Hispanoamérica, con excepciones: Heñín, Fernando, El principio de moralidad en el proceso civil actual, en Peyrano, Jorge W. (director), Principios procesales (Buenos Aires, Rubinzal-Culzoni, 2011), I, pp. 752-756. Existen obras italianas que lo tratan in extenso: Cordopatri, Francesco, L'abuso del proceso (Milano, Cedam, 2000); o lo mencionan a propósito del error judicial y la responsabilidad del Estado. Véase: PICARDI, Nicola, La responsabilità del giudice: la storia continua, en Rivista di Diritto Processuale, 1 (Milano, Cedam, 2007), pp. 295-306.

${ }^{2}$ Para Calamandrei, Piero, Elogio de los jueces, escrito por un abogado (traducción castellana, Buenos Aires, Ejea, 1969), p. 191, la obligación de lealtad procesal que se refiere el Codice italiano respecto de las partes y sus defensores es también aplicable al juez aunque la ley no lo diga expresamente. Ella consiste en dejar consignados en la sentencia los motivos verdaderos que lo han inducido a resolver de una determinada forma y buscar dentro de sí mismo cuáles son sus verdaderos motivos. 
referencia de estudio el caso chileno, pero puede entenderse la sistemática particular de la prospección que se presenta a continuación como inducible a un esquema de carácter general.

Partiendo de la base que el principio de la buena fe procesal posee plena vigencia ${ }^{3}$ y que el magistrado pueda incurrir en actitudes abusivas dentro del proceso $^{4}$, se excluyen de este examen aquellas conductas que son dolosas y que en consecuencia caben dentro del radio de acción del derecho penal5. Tampoco están comprendidos los abusos cometidos en la dictación de una resolución cuya solución está cubierta por el recurso de queja ${ }^{6}$.

${ }^{3}$ Véase, entre otros: Picó i Junoy, Joan, El principio de la buena fe procesal (Barcelona, Bosch, 2003); HazArD, Geoffrey, Abuse of Procedural Rights: A Summary View of the Common Law Systems and Abuse of Procedural Rights: Regional Report for the United States, en TARUFFo - HAZARD (editores), Abuse of Procedural Rights: Comparative Standards of Procedural Fairness (New Orleans, Tulane Law School, 1999), pp. 43-52; Cordopatri, Francesco, L'abuso del processo (Milano, Cedam, 2000); BALESTRO Faure, Myriam, El principio que probibe el abuso de los derechos procesales, en PEYRANO, Jorge (director) Principios procesales ( Buenos Aires, Rubinzal-Culzoni, 2011), I, pp. 801-881; GRASSI DE GOUVEIA, Lucio, Breves consideraçoes acerca do principio da probidade no proceso civil brasileiro, en DIDIER JR, Fredie (editor), Teoría do proceso, panorama doutrinário mundial (Salvador, Iuspodium, 2010), pp. 525-530; ROMERO SEGUEL, Alejandro, cit. (n. 199), pp. 74-77; El principio de la buena fe procesal y su desarrollo en la jurisprudencia, a la luz de la doctrina de los actos propios, en Revista Chilena de Derecho, 30 (enero-abril de 2003) 1, pp. 168-172; Tavolari, Pía, El abuso en el proceso (Santiago, Ediciones Jurídicas, 2004); Buzzacchi, Chiara, L'abuso del processo nel diritto romano (Milano, Giuffrè, 2002), p. 3.

${ }^{4}$ Berizonce, Roberto, El exceso en el ejercicio del poder jurisdiccional, en Studi di Diritto processuale civile in onore di Giuseppe Tazia (Milano, Giuffrè, 2005), I, pp. 318.

${ }^{5}$ Véanse los artículos 79 C.Pol. y 324 COT. Es importante destacar que según la última norma citada, la prevaricación no sería aplicable a la Corte Suprema, lo que a primera vista implica un transgresión al principio de igualdad ante la ley. Sobre el particular, véase: CABALlero Brun, Felipe, El artículo 324 del Código Orgánico de Tribunales y el principio de igualdad en el ordenamiento jurídico chileno, en Revista de Derecho de la Universidad Austral de Chile, 18 (2005) 2, pp. 155-166.

${ }^{6}$ El tratamiento de esa materia está contenida dentro del estudio general de los recursos procesales, considerando que mediante ese tipo de impugnación se busca la invalidación de una resolución judicial. Véanse: Corte Suprema, 9 de marzo de 2011, en: www.legalpublishing.cl, número identificador 48211, visitado el 18 de agosto de 2011; Corte Suprema, 21 de julio de 2010, en: www.legalpublishing.cl, número identificador 44937, visitado el 18 de agosto de 2011; Corte de Apelaciones de Iquique, 3 de junio de 2011, en: www.legalpublishing.cl, número identificador 49826, visitado el 18 de agosto de 2011; Corte de Apelaciones de Santiago, 2 de junio de 2011, en: www.legalpublishing.cl, número identificador 49792, visitado el 18 de agosto de 2011; Corte de Apelaciones de Valparaíso, 21 de marzo de 2011, en: www.legalpublishing.cl, número identificador 48270, visitado el 18 de agosto de 2011. 


\section{ASIMETRÍA DE LOS SUJETOS DE LA RELACIÓN PROCESAL}

La asimetría del proceso civil implica el alejamiento de los sujetos de la relación procesal. Para llegar a esta conclusión se hace necesario comprender que para alcanzar uno de los objetivos del proceso civil, la óptima realización de los derechos subjetivos ${ }^{7}$, las partes y el juez deben situarse en una posición colaborativa $^{8}$, esto significa una posición paralela en altura y distancia ${ }^{9}$.

$\mathrm{El}$ actual paradigma en que se encuentra inserta la figura del juez en el proceso civil, se basa en la autoridad, la jerarquía y la burocracia. Los magistrados son vistos, y se ven a sí mismos, como encerrados en la letra de la ley, escindidos de su realidad material y sociocultural ${ }^{10}$. No se concibe al juez como un representante del Estado y de la expresión democrática en que se

${ }^{7}$ BAPTISTA DA Silva, Ovidio A. Jurisdicción y ejecución en la tradición romano-canónica (Lima, Palestra, 2005), p. 245; passim; KERN, Christoph, Un análisis del derecho procesal civil de EEUUy de Alemania, ponencia efectuada en coloquio sobre la reforma a la justicia civil en Chile (en prensa, Abeledo Perrot).

${ }^{8}$ La posición colaborativa de los sujetos procesales constituye uno de los vértices de la propuesta formal valorativa del proceso. Es un tema complejo y extenso que responde a la siguiente pregunta: ¿Dónde encuentran el equilibrio las facultades o poderes del juez en relación con las facultades de las partes? El principio de colaboración otorga una respuesta. Tal directriz implica que la sentencia sólo puede constituirse como el resultado mancomunado de todos los sujetos del proceso. De esta manera es necesario un juez activo en correlación a la participación de las partes de forma también activa y leal, pues como asevera Perelman, la personalidad de los jueces desempeña un papel esencial en la administración de justicia, y son necesarios, en un Estado bien gobernado, jueces competentes e imparciales. Se excluye así una visión autoritaria del papel del juez mediante un permanente concurso de actividades de los sujetos procesales. Sobre el particular, véase: Perelman, Chaïm, Ética e direito (Sao Paulo, Martins Fontes, 1999), p. 516. Marinoni, Luiz - Mitidiero, Daniel, Do projecto do cpc (San Pablo, Dos tribunais, 2010), pp. 87-88; Alvaro de Oliveira, Carlos Alberto, Del formalismo en el proceso civil, propuesta de un formalismo valorativo (Lima, Palestra, 2007), p. 286.

${ }^{9}$ Gozaíni, Osvaldo, La conducta en el proceso (Buenos Aires, Platense, 1988), p. 9.

${ }^{10}$ Resulta innegable que el juez en su misión está influenciado válidamente por todos los factores que lo han formado no sólo como jurista sino además como un ser social. Es por ello que pretender a un juez autómata que aislado de toda vertiente cultural (política, económica, religiosa, etc.) resuelva los casos, es utópico. El juez es en consecuencia y como Ross señala: un "fenómeno cultural”. Ross, Alf, On Law and Justice (Clark, New Yersey, 2004), pp. 99-100. Véase también: Escandón Alomar, Jesús, La concepción de la Ciencia del Derecho y el concepto del Derecho vigente en el pensamiento jurídico de Alf Ross, en Revista de Derecho de la Universidad Austral de Chile, 12 (2001) 2, pp. 169-174. Un ensayo de lo planteado respecto a los jueces italianos, enfocado a la labor creadora del derecho en: Fazzalari, Elio, Conocimiento y valores (Lima, Communitas, 2008), pp. 37-61. 
inserta su ministerio, necesariamente activos y creativos ${ }^{11}$. Aquella percepción es asumida por las partes y el órgano jurisdiccional quién, de acuerdo a ella, establece una posición dominante y formalista sobre todos los aspectos del proceso, situación que quizá en principio pudo causar reticencia a las partes, pero a la que luego, paulatinamente, se acostumbraron. Las razones para haber alcanzado tal postura obedecen a una multiplicidad de factores, puesto que, como es razonable pensar, siendo el proceso un fenómeno inmerso en la contingencia social, los motivos de sus constantes mutaciones obedecen a los mismos factores que motivan el cambio social. Dentro de esas causas, se puede encontrar al menos dos que nos pueden dar luces sobre la cuestión, a saber: la pérdida del carácter dialéctico del proceso y la equivocada idea del juez como "tercero imparcial"12.

\section{La pérdida del carácter dialéctico del proceso.}

El proceso civil en gran medida está impregnado del método dialéctico ${ }^{13}$. Es así concebido como un método contra argumentativo de solución de conflictos. En esa concepción, todos los sujetos deben colaborar argumentativamente para el desarrollo y consecución de la Litis. juezy partes se sitúan en posiciones similares y ninguno de ellos pierde sus herramientas: el magistrado, la facultad de dictar sentencia y proveer lo necesario para su consecución; y las partes, sus potestades -sobre todo el plano argumentativo del proceso-. Las partes pueden hacer sus alegaciones con entera libertad o decidir sobre la marcha o fin del proceso. Como se observa, todos los intervinientes conservan sus potestades que son distintas unas de otras, lo que hay que comprender es que, no obstante las diferencias, el plano de isonomía no se pierde, sino que se produce sobre la labor que ejercen todos los actores del proceso judicial cuando son consientes que desarrollan la función pública de administrar justicia. En ella hay, más allá de las diferencias de forma anotadas, un aspecto esencial: la voluntad de los sujetos de arreglar una contienda.

Lo que pudiese producir algún grado de incertidumbre dentro del esquema señalado es cómo se entiende en él el concepto de autoridad. Si por autoridad se entiende que una persona que sobre la otra se sitúa autoritariamente para prescribir o mandarle a ejercer determinada conducta;

${ }^{11}$ Alvaro de Oliveira, Carlos Alberto (cit. n. 8), p. 16.

${ }^{12}$ Bordalí Salamanca, Andrés, Análisis crítico de la función e independencia judicial en el Derecho chileno, en Couso, Jaime - Atria, Fernando (editores), La judicatura como organización (Santiago, Instituto de Estudios Judiciales, 2007), p. 6.

${ }^{13}$ Sobre el particular: García Amado, Juan Antonio, Tópica, Derecho y método jurídico, en Doxa, 4 (1987), pp. 161-188; Guzmán Brito, Alejandro, Historia de la interpretación de las normas en el Derecho romano (Santiago, Ediciones del Instituto de Historia del Derecho Juan de Solórzano y Pereyra, 2000), p. 38. 
o como una persona que despóticamente dirige sus facultades, ese tipo de autoridad no se encuentra dentro del esquema adecuado. La autoridad, en un proceso de corte argumentativo, debe entenderse no como la persona, sino como el señorío de aquella predispuesta a ordenar el debate con miras a un objetivo.

Sucede que en el tiempo, ese enfoque conceptual homogéneo sufre un quiebre como consecuencia del avance del pensamiento jurídico hacia los canales propios del racionalismo cartesiano ${ }^{14}$. Su inicio se encuentra en el método lógico introducido en la disciplina jurídica por influjo de Pierre de la Ramée (Petrus Ramus), un experto en Dialéctica, a quien, en efecto, siguieron algunos sistemáticos del Derecho ${ }^{15}$. El filósofo francés se rebela contra el método aristotélico imperante en su época, que se sustentaba sobre la Retórica y la Tópica como herramientas para ordenar y enseñar las disciplinas sociales y las construcciones intelectuales surgidas a partir de ellas, entre ellas la concepción del iudicium vigente hasta el siglo XVII. Ramus utilizó métodos propios de la ciencia de la naturaleza para la búsqueda de la verdad, pero no de una razón absoluta para el descubrimiento de las cosas, sino una verdad probable con aspiraciones de certeza. Su propuesta consiste en ordenar la materia resumida de acuerdo a criterios de generalidad y especialidad, actividad propia de la actual dogmática jurídica. Como se advierte, es Ramus quién impulsa el método utilizado para el actual análisis y clasificación del Derecho. Este plano intelectual deja cimentadas las bases para que la corriente del iluminismo y, definitivamente, la revolución francesa ${ }^{16}$ hagan perder la dimensión retórica del proceso y se pase a un proceso judicial puesto sobre un plano de paridad a otro de carácter "asimétrico" ${ }^{17}$. Sabida es la visión de los revolucionarios franceses frente a uno de los representantes del poder

${ }^{14}$ Baptista da Silva, Ovidio, Jurisdicción y ejecución en la tradición romanocanónica (Lima, Palestra, 2005), pp. 296-298.

15 "La tecnica proposta da Pierre de la Ramée e recepita dai giuristi è semplicemente il procedimento sintetico: egli raccomanda infatti di disporre la materia secondo criteri decrescenti di generalità e difficoltà e di esporla passando dal generale al particolare e dal complesso al semplice": Losano, Mario, Sistema e struttura nel diritto: Dalle origini alla scuola storica, (Milano, Giuffrè, 2002), I, p. 39.

${ }^{16}$ PICARDI, Nicola, Il giudice naturale, principio fondamentale a livello europeo, en Didier Jr. Fredie (editor), Teoria do processo. Panorama doutrinario mundial (2010), II, pp. 659-669.

${ }^{17}$ Las ideas desarrolladas en este punto consideran además la promulgación del code de procédure civile de 1806 que reguló el proceso de un modo simple y racional, eliminando las inútiles formalidades con que estaba precedido el procedimiento civil. Cuestión que se irradió a las demás legislaciones procesales europeas. Liebman, Enrico Tulio, Manuale di Diritto processuale civile (Milano, Giuffrè, 1957), I, pp. 19-22. 
tiránico del rey: la figura del juez ${ }^{18}$. El delirio revolucionario lo sitúa en una posición que, con suerte, se limita a regular aspectos mecánicos del litigio y dictar sentencia que progresivamente lo distancia de las partes. Pareciere que cualquier intervención del juez intranquiliza los ánimos repulsivos a los vestigios reales dejados en la guillotina ${ }^{19}$. Así, la figura judicial pierde sustento en su connotación original y en realidad en toda otra connotación, sea ésta positiva o negativa. Las partes están cada vez más alejadas de la magistratura y más desconfiadas de ella. El juez, por tanto, se queda cada vez más aislado de los participantes de la contienda. A ello se une un proceso legislativo post revolucionario que cercena sus facultades legales y así sucesivamente, la figura del Juezse va cimentando sobre una connotación más individual que colaborativa ${ }^{20}$. La autoridad ya no se forja en base a una razón dialéctica y democrática, sino que se encierra en sí misma y no encuentra otro fundamento que la posición dominante sobre las partes. Aquella forma cuaja finalmente en los sistemas jurídicos continentales, entre ellos el chileno, donde asume gran preeminencia.

\section{El juez como tercero imparcial.}

Las ideas post revolución que rigen sin contrapeso durante un largo período no se agotan en las consecuencias mediatas vistas en el apartado anterior, sino que trascienden lo suficiente para incoar en las conciencias de los operadores el paradigma del juez como "tercero imparcial" ${ }^{21}$. En realidad, lo que sucede es que la comprensión errónea del concepto aludido constituye la concreción de un fenómeno progresivo guiado por afanes políticos y escasamente racionales. La imparcialidad del juzgador, tiene su fundamento en el derecho de los justiciables a ser tratados por igual ${ }^{22}$, y no implica que deba permanecer ajeno al desarrollo del proceso, sino sólo que

${ }^{18}$ Tarello, Giovanni, Storia della cultura giuridica moderna (Bologna, Mulino, 1976), II, pp. 262-298; MARINONI, Luiz Guilherme, Aproximación crítica entre las jurisdicciones del civil law y del common law y la necesidad de respeto a los precedentes en Brasil, en Constitución y proceso (Lima, Ara, 2009), p. 83.

${ }^{19}$ Lo dicho aquí no desconoce las características del ancien régime, los inconvenientes de una judicatura asentada en títulos nobiliarios. El poder que se manifiesta en que las cortes de más alto grado (parlamentos) asumían la función de custodia y garantía de las leyes fundamentales, y la nula dependencia jerárquica burocrática desde la judicatura hacia el rey. PiCARDI, Nicola, cit. (n. 16), p. 659.

${ }^{20}$ Alvaro de Oliveira, Carlos Alberto, cit. (n. 8), pp. 21-23.

${ }^{21}$ Cavallone, Bruno, Un "frivolo amor propio" precognizione e imparzialità del giudice civile en Studi di diritto processuale civile in onore di Giuseppe Tazia (Milano, Giuffrè, 2005), I, p. 19; Alcalá - Zamora, Niceto, Estudios de teoría e historia del proceso (Mexico, E. J. U., 2001), III, p. 46.

${ }^{22}$ Véase artículo 9 del Código Iberoamericano de Ética Judicial, disponible en: 
debe permanecer distante de las posiciones subjetivas de las partes. Debe tenerse en cuenta lo anterior para entender bien que la dirección del juez sobre los aspectos procesales no implica parcialidad en su función. Un juez parcial es el que llevado por los prejuicios o intereses propios encamina una contienda a la posición que comparte con alguna de las partes, no necesariamente buscando un beneficio evidente. La confusión se produce porque suele aludirse al juez no sólo como imparcial, además se agrega el término "tercero" para resaltar la idea de su imparcialidad, entonces se dice que el juez no es parte y por tanto debe alejarse de las partes en todos los planos del proceso, incluso en el instrumental. Si a eso se agrega una comprensión exagerada del principio dispositivo, se ve a un juez aun más alejado, ya no sólo de las partes, sino también del proceso mismo. El juez, cuando dirige el proceso es imparcial, puesto que no busca el beneficio de ninguna de las partes consideradas aisladamente sino que el de ambas y el de la sociedad, va en búsqueda de un proceso más eficiente y rápido que en esos aspectos satisfará incluso al litigante perdedor ${ }^{23}$.

En realidad, lo que sucede es que la locución "tercero" no tiene relación con la parcialidad o imparcialidad del juzgador, sino con otro aspecto de la ética judicial: la independencia ${ }^{24}$.

http://www.cumbrejudicial.org/c/document_library/get_file?folderId=27110\& name=DLFE1306.pdf, visitado el 28 de julio de 2011.

${ }^{23} \mathrm{La}$ imparcialidad es un principio de ética que guía el comportamiento de los jueces, ampliamente tratada por el Código iberoaméricano de ética judicial, en los artículos del 9 al 17. Véase: BARberio, Sergio - García Solá, Marcela, Lineamientos de los principios dispositivo e inquisitivo, en Peyrano, Jorge (director) Principios procesales (Buenos Aires, Rubinzal - Culzoni, 2011), I, pp. 145-161; Picó I. Junoy, Joan, Los principios dispositivo y de aportación de parte: significado actual, en PEYRANO, Jorge (director) Principios procesales (Buenos Aires, Rubinzal - Culzoni, 2011), I, pp. 161 - 199.

${ }^{24}$ Resulta que para que le juez pueda ser realmente "tercero" respecto a los intereses en conflicto, deberá ser independiente de los otros poderes del Estado (independencia externa) y de los demás componentes del orden judiciario (interna), frente a las presiones que ellos puedan ejercer para compelerlo a ejercer una determinada conducta judicial. En la práctica, independiente y tercero son usados como sinónimos. Pero con mayor precisión la independencia es el medio a través del cual se garantiza la imparcialidad (tercero) del juez. Así, el juez no nace tercero sino que deviene, porque existe un complejo de instrumentos de naturaleza constitucional y procesal que la aseguran la independencia. Los constitucionales son conocidos, dentro de los que se cuenta inamovilidad y el hecho que el juez es plenamente libre en tomar decisiones. Pero, en este segundo caso, no de la forma tosca como se viene desarrollando en Chile, sino que, con fundamentos que ratifiquen un ejercicio efectivo de la libertad de tomar esas decisiones, que como base debe contener el reconocimiento de la doctrina mayoritaria imperante, si se quiere, sostenida por la Corte Suprema, y pormenorizadamente las razones del cambio. Lo anterior implica hacerse cargo punto por punto de la tesis permanente, 


\section{LA EQUIVALENCIA FORMAL}

ENTRE LOS IMPERATIVOS DEL JUEZ Y LAS PARTES

Para hablar de un plano simétrico de la relación procesal se debe establecer el patrón común que un imperativo posee respecto a todos los sujetos procesales. Para ello resulta casi una obviedad decir que el juez, como uno de los sujetos que integra la relación jurídica procesal, le asisten deberes específicos $^{25}$. Se subentiende que las funciones del juez dentro del proceso son distintas a las que les compete cumplir a las partes y, por ende, el contenido del imperativo es diverso para uno y otras. No obstante, los imperativos procesales comunes -los deberes- ostentan igual estructura para todos los sujetos; poseen un núcleo conformado por una subespecie que a su vez está compuesta por un sujeto, un predicado y un valor subyacente, como también una consecuencia en caso de infracción.

Lo relevante es que en este sentido analítico, el plano de equivalencia formal que se plantea se cumple a cabalidad, por cuanto el Estado, en interés del bien social, provee categorías conductuales que poseen un contenido ético y una consecuencia para el caso de su incumplimiento. Ello es aplicable a todos los sujetos que conforman la relación jurídica procesal. Estas consisten en penas administrativas, pecuniarias, restrictivas de derechos, o el pago de indemnizaciones ${ }^{26}$. El juez está sometido a tantas responsabilidades como aquellas a las que lo están las partes, pero la isonomía no culmina en ese argumento, sino que converge en uno más concreto, que está en plena armonía con la necesaria colaboración que los participantes de la relación deben ejecutar: todos los sujetos procesales buscan un mismo objetivo ${ }^{27}$ :

como sostiene la doctrina Italiana, respetando el principio del stare decisis. Véase: RicCI, Gianfranco, Principi di Diritto processuale generale (Torino, 1998, Giappicheli), pp. 9-11; GARGarella, Roberto, La dificultad de defender el control judicial de las leyes, en Isonomia, 6 (1997), pp. 55-70.

${ }^{25}$ Lent, Friedrich, Obblighi e oneri nel processo civile, en Rivista di Diritto Processuale, 9 (Padova, Cedam, 1954) 1, pp. 150-158; Couture, Eduardo, Introducción al estudio del proceso civil2 (2a edición, Buenos Aires, Arayú, 1953); Tavolari Oliveros, Raúl, Estudios de Derecho procesal (Valparaíso, Edeval, 1990); Fazzalari, Elio, Conocimiento y valores (Lima, Communitas, 2008), pp. 37-61.

${ }^{26}$ Permanece al margen de este discurso la figura del error judicial, puesto que obedece a otros motivos y fines que los descritos aquí. Sobre el particular: Malem Seña, Jorge, El error judicial y la formación de los jueces (Barcelona, Gedisa, 2008).

${ }^{27}$ Es importante señalar que algunos autores afirman que al juez le asisten "poderesdeberes". Exponen que de esta manera, no se produce el inconveniente de que una parte piense que el juez tiene deberes y a su vez el juzgador piense que solo tiene facultades respecto de lo mismo. Según los que piensan así, esa disímil percepción del lenguaje puede llevar al estanco del proceso al no tomar la iniciativa ninguno de los participantes frente al carácter recomendativo de la facultad. Lo cierto es que la distinción es innece- 
llegar a la justa decisión del asunto ${ }^{28}$.

\section{Actitudes judiciales constitutivas de abuso procesal}

Dentro de una relación jurídica procesal simétricaa ${ }^{29}$, conforme a lo razonado en los parágrafos anteriores, deben considerarse dos parámetros: el abuso procesal que se concreta por la violación de un deber judicial (intraprocesal) y el abuso por causa de la violación de una norma disciplinaria que gobierna el ejercicio de la posición jurídica del juez ${ }^{30}$.

saria por dos razones. Primero, la pretendida reafirmación del término es casi tautológica, porque insiste en la idea de la necesaria utilización de los deberes por parte del juez, lo que está suficientemente plasmado en la aspiración de un proceso civil eficiente y en las disposiciones que regulan la función judicial; también está implícito en la idea general que se viene desarrollando aquí. Segundo, aquella locución puede resultar incluso contradictoria, ya que los poderes suelen diferenciarse notoriamente de los deberes, los primeros son usados en forma discrecional y se entregan en estados de excepción cuando se necesita de una categoría superior al deber para superar una contingencia. Cfr. Sentís Melendo, Santiago, Teoría y práctica del proceso (Buenos Aires, 1959), III, p. 108; Tavolari Oliveros, Raúl, Tavolari Oliveros, Raúl, Estudios de Derecho procesal (Valparaíso, Edeval, 1990); Masciotra, Mario, La conducta procesal de las partes (Buenos Aires, Ad hoc, 2005), pp 13-23; GozAíni, Alfredo Osvaldo, Los cambios deparadigmas en el derecho procesal el "neoprocesalismo", en Revista de Processo (Dos Tribunais, 2007), p. 67. La locución también es usada en el proyecto de código procesal civil para Iberoamérica.

${ }^{28}$ Esto puede estar en relación a la búsqueda de la verdad material en el proceso, entendida como la verdad de los hechos, o la verdad formal, como la posición de algunas de las partes que en él intervienen, teniéndose por cierta en la sentencia la posición por una de ellas asumida. Vèase: TARUfFo, Michele, La prova dei fatti guiridici (Giuffrè, Milano, 1992), passim.

${ }^{29} \mathrm{Si}$ bien el ordenamiento procedimental chileno se refiere a las conductas judiciales abusivas, su tratamiento legislativo es disperso y no está rotulado directamente como "abuso", "mala fe", o locuciones semejantes. Existe un caso en la jurisprudencia que se refirió expresamente a la posibilidad de abuso procesal por parte del juez, aunque en materia procesal penal. La Corte de Apelaciones de Concepción señaló que la actuación de una juez de garantía era contraria al instituto cuando la magistrado no procedió a verificar la identidad de un asistente a la audiencia, en circunstancia que no poseía su documento de identificación; y, en cambio, libró órdenes de detención en su contra. Corte de Apelaciones de Concepción, 16 de agosto de 2010, rol No 75-2010, en www.legalpublisching.cl, visitado el 11 de agosto de 2011. Jurisprudencia que está en consonancia con una de las tesis que se se plantean en este trabajo, que es plenamente posible que el juez sea uno de los transgresores del principio.

${ }^{30}$ Cordopatri, Francesco, cit. (n. 1), p. 750. 


\section{Clasificación}

El abuso intraprocesal comprende las arbitrariedades que se cometen en el manejo del proceso. Así ocurre por ejemplo, cuando el juez incurre en la injustificada dilación de la tramitación del proceso. Este deber de celeridad está establecido a modo de enunciado general en el artículo 319 COT.: "Los jueces están obligados a despachar los asuntos sometidos a su conocimiento en los plazos que fja la ley o con toda la brevedad que las actuaciones de su ministerio lespermitan [...]".

La secuela del incumplimiento del deber implícito en la disposición no está establecida en ella, se verá luego que cae dentro de las consecuencias generales dispuestas por la ley para estos casos. No obstante, existe una norma específica que impone al juez el deber de dictar la sentencias dentro de un determinado plazo, el fin de la disposición es, sin duda, impedir la dilación injustificada de la dictación de la sentencia y, en consecuencia, del proceso. No cabe duda que esa es una actitud abusiva del magistrado, como la señalada en el artículo 162 CPC.: "La sentencia definitiva en el juicio ordinario deberá pronunciarse dentro del término de sesenta días, contados desde que la causa quede en estado de sentencia./ Si el juez no dicta sentencia dentro de este plazo, será amonestado por la Corte de Apelaciones respectiva, y si a pesar de esta amonestación no expide el fallo dentro del nuevo plazo que ella le designe, incurrirá en la pena de suspensión de su empleo por el término de treinta dias, que será decretada por la misma Corte".

Se pueden observar que los efectos del acto dilatorio no producen la invalidación del acto procesal de fondo, que en este caso sería la anulación de la sentencia por el retardo, ésta queda impoluta frente a la tardanza y las consecuencias sólo las recibe el juez ${ }^{31}$. También, el juez asume otros deberes dentro del proceso relacionados con su marcha, que no son tan explícitos como el citado recién, pero se desprenden del apartado legislativo, como el deber de dirección ${ }^{32}$. En ese sentido, nada impide que las actitudes contradic-

${ }^{31}$ Ibíd., p. 755.

${ }^{32}$ En general, la dirección del proceso es el instituto que orienta al juez a tomar las riendas del litigio civil para la consecución de un pleito correcta y eficientemente tramitado. De este instituto emana un deber para el juez en la medida que está compelido por el ordenamiento jurídico para cumplir con el fin enunciado. El proceso, no es una simple ordenación de actos de carácter formal que transcurren aleatoriamente hasta su fin. El proceso es un fenómeno dinámico que se desenvuelve escalonadamente en el tiempo y que requiere de una fuerza de progresión para funcionar. El impulso debe ser ordenado para llegar a su objetivo que es decidir sobre el derecho de los justiciables que en él intervienen. La tarea no puede ser exclusivamente dejada a las partes pues, la función pública de administrar justicia, que es el canal por el que el proceso se desenvuelve, es una tarea que delega el orden social al poder estatal (Damaska). Entonces el rol del juez como sujeto imparcial no puede ser otro que dirigir el proceso para el fin expuesto, lo que significa 
torias de los jueces ejercidas sobre la dirección del proceso, cuando revistan cierta entidad, puedan quedar comprendidas en los efectos y sanciones que se tratan aquí. También el deber de fundar las resoluciones. Éste consiste tanto en consignar argumentos que justifiquen una decisión como que aquellos argumentos sean consecuentes con los hechos sobre los que versa el proceso. Así no cumple con este deber el o los magistrado que se limitan a confirmar o denegar una resolución -sin motivos fundantes-si están llamados a revisarlas, como aquellos que no expresan todas y cada una de las razones que se tienen en vista para arribar a un fallo ${ }^{33}$.

tomar el control, del proceso para darle forma, orden, rectitud, coherencia y celeridad. $\mathrm{Al}$ juez, en consecuencia, si se espera de él una actitud cabal, se le debe exigir obrar con los mismos valores. Es importante tener presente el sistema procedimental en el cual será ejercida la dirección; no será lo mismo un sistema escrito que uno por audiencias. Un sistema escrito, por su propio carácter presenta formas rígidas que, si bien no obstan la función directiva, sí la dificultan. El manejo de un proceso de esas características es menos cercano a los sujetos que en él intervienen, lo que es un aspecto relevante en el ejercicio efectivo de dicha dirección. Un sistema oral, en cambio, sí posee esas virtudes, lo que ha conducido a que hoy en día se apunte a la oralidad en los sistemas procesales del mundo. En ese escenario, el proceso requiere una mayor intervención del juez, pues, entendiendo la dinámica de las audiencias que se efectúan en tal sentido y los principios que la rigen, como la inmediación y la búsqueda de soluciones colaborativas, la figura del magistrado naturalmente cobra mayor preponderancia, protagonismo e interacción con las partes. Un juez en extremo formalista, que no empatice con las partes, no podrá llegar a un óptimo resultado. En doctrina se habla de dos tipos de dirección, una formal y otra material. La primera, a grandes rasgos, se refiere o está fundado sobre todas aquellas normas que otorgan el impulso procesal al órgano sentenciador y que lo compelen a llevar adelante la misión de hacer avanzar el proceso con celeridad. La dirección material, omnipresente en el sistema procesal civil alemán, se plantea una misión del juez para esclarecer los hechos y el derecho invocado por las partes en el pleito, sin la posibilidad de que éste pueda extenderse a otras situaciones que, aunque estén vinculadas con el litigio, no fueron formuladas por las partes en sus presentaciones. Sobre el particular, véase: parágrafo 14 de los Principles of transnational civil procedure (ALI/UNIDROIT), disponibles en: http://www.unidroit.org/english/studies/study76/main.htm; CAPPELLETTI, Mauro, El proceso civil en el Derecho comparado (Lima, Ara, 1973), p. 69; DAMASKA, Mirjan, The Faces of Justice and State authority (Yale University Press, 1986), pp. 134-135. Prütting, Hans, Presentación de documentos y dirección del proceso, en Pérez Ragone, Álvaro J. - Ortiz Pradillo, Juan Carlos, Código Procesal Civil alemán, Traducción con un Estudio Introductorio al Proceso Civil Alemán Contemporáneo (Montevideo, Konrad Adenauer Stiftung, 2006); Del Claro, Roberto, Direçao material do proceso (Tesis Doctoral, Sao Paulo, 2009), p. 168.

${ }^{33}$ Esto dice relación especialmente con las máximas de la experiencia (sana crítica) como un patrón válido de análisis y juzgamiento. Ello por cuanto es fundamental que el magistrado de sus razones no sólo jurídicas que influyen en su decisión, sino que todas aquellas que digan relación con sus patrones culturales (Ross). Esto es imprescindible por cuanto si no las cita, veda también el derecho recursivo que tiene quien se sienta 
En cuanto a las actitudes abusivas disciplinarias que se refieren a las actividades judiciales que no recaen directamente sobre el iter procesal y no afectan su marcha normal ${ }^{34}$, se encuentran aquellas situaciones, entre otras, que el juez acepta compromisos con algunas de las partes involucradas en una causa que él dirige, expresa o insinúa privadamente su juicio respecto de los negocios que por la ley es llamado a fallar, escucha la alegación de las partes o se deja influenciar por ellas, etc. ${ }^{35}$. Para estos eventos la ley es específica en señalar que esas actitudes, que se encuentran dentro de un catálogo bastante amplio, no le son permitidas en el desarrollo de su ministerio, y en general tienen concordancia con actitudes incorrectas que permean su imparcialidad y que atentan contra el decoro de la función judicial ${ }^{36}$.

\section{Efectos.}

De la conjugación de aspectos y normas vistas en el acápite precedente se puede concluir que para el evento de las situaciones de abuso intraprocesal, cuando el deber está especificado en la norma, por lo general ella misma contiene la sanción que resulta aplicable en caso de infracción, mientras que las actitudes extraprocesales quedan comprendidas bajo un acápite general sancionatorio que impone desde amonestación hasta suspensión del cargo ${ }^{37}$.

En todo caso, los deberes implícitos, ya sean enfocados al manejo directo del proceso como los extraprocesales que no poseen una sanción específica, igualmente pueden quedar comprendidos dentro de la generalidad del mismo artículo, pues éste no distingue como lo hace su antecesor.

La otra particularidad de los efectos de las actitudes judiciales abusivas acontece en el mecanismo por el cual se pueden hacer valer las responsabilidades que emanan de ellas. Resalta una fiscalización oficiosa constante de los escalones superiores de la pirámide judicial hacia abajo ${ }^{38}$, cuyo fundamento primario se origina a partir del texto constitucional que confiere a la Corte

perjudicado con ella. En efecto, la falta de información de los móviles que tuvo el sentenciador para fallar, no permite el cotejo con aquellos que desde otro punto de vista, si éste es admisible, pueden resultar correctos, o se decidan como correctos por el ente revisor. Sobre la tradición de cultura del juez véase la n. 10.

${ }^{34}$ Es necesario recordar que se hace referencia en este estudio a cualquier procedimiento en que el juez pueda actuar, así sus actitudes inconducentes pueden manifestarse en un proceso cautelar, ejecutivo, sumario etc.

${ }^{35}$ Véanse los artículos 316, 317, 318 y 320 CPC.

${ }^{36}$ C. A. de Antofagasta, 15 de junio de 2009, en www.legalpublishing.cl, número identificador 42153, visitado el 10 de agosto de 2011.

${ }^{37}$ Artículo 537 COT.

${ }^{38}$ Aldunate Lizana, Eduardo, La constitución monárquica del poder judicial, en Revista de Derecho de la Universidad Católica de Valparaíso, 22 (2001), p. 205. 
Suprema la superintendencia correctiva de todos los tribunales de la República $^{39}$, incluso la Corte Suprema se fiscaliza a sí misma ${ }^{40}$. Luego, existe una serie de disposiciones orgánicas que regulan con mayor precisión el contenido de ese poder disciplinario como de los demás tribunales de la República en uso de esas mismas facultades.

A las partes se les franquea una acción específica comúnmente denominada "queja disciplinaria" ${ }^{41}$ que les permite la posibilidad de deducir su reclamo en un procedimiento sumario y sin forma de juicio que debe llevarse ante el tribunal superior de aquel que se trate, quién deberá resolverlo ${ }^{42}$.

En cualquier caso, todos los jueces tienen responsabilidad civil por sus actitudes.

\section{CONCLUSIÓN}

El proceso civil debe asentarse en una estructura simétrica para su progresión. En un plano de igualdad entre las partes y el juez con el objeto de contribuir al desarrollo del proceso. Uno de los vértices -el juzgador- es el ente encargado de resolver la contienda y en su misión no puede permanecer pasivo, pero tampoco podrá actuar contraviniendo los derechos de las partes. En suma, se trata de propender al correcto y eficiente resultado del litigio que se manifestará en la medida en que la actitud del sentenciador no resulte cuestionada, en cuyo caso la contravención se produce si el juez no cumple alguno de los deberes que el sistema jurídico le encomienda. Aquellos deberes nacen de las necesidades que plantea una administración de justicia eficiente. Varias son las formas en que tribunal puede trasgredir la asimetría

\footnotetext{
${ }^{39}$ Artículo 82 C.Pol.

${ }^{40}$ Artículo 541 COT.

${ }^{41}$ Véanse los artículos 535, 536, 537 y 538 y 547 COT.
}

${ }^{42} \mathrm{La}$ jurisprudencia en reiteradas ocasiones realiza la distinción entre el tipo de acción de la queja disciplinaria y el recurso de queja (también llamada queja propiamente tal). La diferencia está en que este último se establece en contra de resoluciones donde se pudo cometer falta o abuso por parte de los magistrados, mientras que la queja se constituye como una especie de reclamo por las faltas en la conducta ministerial de los jueces. El objeto de uno y otro son por tanto distintos. El recurso busca la invalidación de la resolución y la amonestación, mientras que la queja sólo tiene por objeto obtener la sanción del juez. Así está establecido además en el numeral 14 del autoacordado sobre tramitación y fallo del recurso de queja de 1972. Véanse: Corte Suprema, 17 de octubre de 1995, en: www.legalpublishing.cl, número identificador 13687, visitado el 19 de agosto de 2011; Corte Suprema, 12 de abril de 1995, en: www.legalpublishing.cl, número identificador 13444, visitado el 19 de agosto de 2011; Corte Suprema, 25 de abril de 1991, en: www.legalpublishing.cl, número identificador 11204, visitado el 19 de agosto de 2011; Corte Suprema, 18 de octubre de 1989, en: www.legalpublishing.cl, número identificador 10851, visitado el 19 de agosto de 2011. 
y colaboración que aquí se postula: si el juez no actúa con prontitud, rompe el deber de celeridad y por tanto recibe las consecuencias previstas en el sistema legal. Se debe tener presente que así como le es exigible a las partes el cumplimiento de los deberes que emanan del principio de la buena fe procesal también ellas les pueden exigir al juez que obre de la misma manera. Por lo anterior es plenamente posible afirmar que el juez puede ejercer conductas constitutivas de abuso procesal que pueden ser remediadas a través de los mecanismos que actualmente establece la legislación. No obstante, en vista a la promulgación de un nuevo código procesal civil, sería preferible una norma expresa que prevea expresamente la posibilidad de abuso judicial y establezca con claridad las consecuencias a su infracción.

\section{BIBLIOGRAFÍA}

Alcalá-Zamora, Niceto, Estudios de teoría e historia del proceso (Mexico, E. J. U., 2001).

Aldunate Lizana, Eduardo, La constitución monárquica del poder judicial, en Revista de Derecho de la Universidad Católica de Valparaíso, 22 (2001).

Álvaro de Oliveira, Carlos Alberto, Del formalismo en el proceso civil. Propuesta de un formalismo valorativo (Lima, Palestra, 2007).

BALESTro Faure, Myriam, El principio que prohíbe el abuso de los derechos procesales, en Peyrano, Jorge (director), Principios procesales (Buenos Aires, Rubinzal-Culzoni, 2011), I.

BAPTISTA Da Silva, Ovidio A. Jurisdicción y ejecución en la tradición romano-canónica (Lima, Palestra, 2005).

BArberio, Sergio - García Solá, Marcela, Lineamientos de los principios dispositivo e inquisitivo, en Peyrano, Jorge (director), Principios procesales (Buenos Aires, Rubinzal-Culzoni, 2011), I.

BerIzONCE, Roberto, El exceso en el ejercicio del poder jurisdiccional, en Studi di diritto processuale civile in onore di Giuseppe Tazia (Milano, Giuffrè, 2005), I.

Bordalí Salamanca, Andrés, Análisis crítico de la función e independencia judicial en el Derecho chileno, en Couso, Jaime - Atria, Fernando (editores), La judicatura como organización (Santiago, Instituto de Estudios Judiciales, 2007).

Buzzacchi, Chiara, L'abuso del processo nel diritto romano (Milano, Giuffrè, 2002).

Caballero Brun, Felipe, El artículo 324 del Código Orgánico de Tribunales y el principio de igualdad en el ordenamiento jurídico chileno, en Revista de Derecho Universidad Austral de Chile, 18 (2005) 2.

Calamandrei, Piero, Elogio de los jueces, escrito por un abogado (Buenos Aires, Ejea, 1969).

Cappelletti, Mauro, El proceso civil en el Derecho comparado (Lima, Ara, 1973).

CAVAllone, Bruno, Un "frivolo amor propio" precognizione e imparzialità del giudice civile, en Studi di diritto processuale civile in onore di Giuseppe Tazia (Milano, Giuffrè, 2005), I.

Cordopatri, Francesco, L'abuso del proceso (Milano, Cedam, 2000). 
Couture, Eduardo, Introducción al estudio del proceso civil ( $2^{\mathrm{a}}$ edición, Buenos Aires, Arayú, 1953).

Damaska, Mirjan, The Faces of Justice and State Authority (Yale University Press, 1986).

Del Claro, Roberto, Direçao material do proceso (Tesis Doctoral, Sao Paulo, 2009).

Escandón Alomar, Jesús, La Concepción de la Ciencia del Derecho y el concepto del Derecho vigente en el pensamiento jurídico de AlfRoss, en Revista de Derecho Universidad Austral de Chile, 12 (2001) 2.

Fazzalari, Elio, Conocimiento y valores (Lima, Communitas, 2008).

García Amado, Juan Antonio, Tópica, Derecho y método jurídico, en Doxa, 4 (1987), pp. 161-188.

Gargarella, Roberto, La dificultad de defender el control judicial de las leyes, en Isonomia, 6 (1997).

GozAíni, Alfredo Osvaldo, Los cambios deparadigmas en el Derecho procesal el "neoprocesalismo", en Revista de Processo (Dos Tribunais, 2007).

GozaÍni, Osvaldo, La conducta en el proceso (Buenos Aires, Platense, 1988).

Grassi De Gouveia, Lucio, Breves consideraçoes acerca do principio da probidade no proceso civil brasileiro, en Didier JR, Fredie (editor), Teoria do proceso. Panorama doutrinário mundial (Salvador, Iuspodium, 2010),II,

GuZmán Brito, Alejandro, Historia de la interpretación de las normas en el derecho romano (Santiago, Ediciones del Instituto de Historia del Derecho Juan de Solórzano y Pereyra, 2000).

Hazard, Geoffrey,. Abuse of Procedural Rights: A Summary View of the Common Law Systems and Abuse of Procedural Rights: Regional Report for the United States, en TARuffo- Hazard (editores) Abuse of Procedural Rights: Comparative Standards of Procedural Fairness (New Orleans, Tulane Law School, 1999).

HeÑín, Fernando, Elprincipio de moralidad en el proceso civil actual, en PEYRANo, Jorge (director), Principios procesales (Buenos Aires, Rubinzal - Culzoni, 2011), I.

KERN, Christoph, Un análisis del Derecho procesal civil de EE.UU. y de Alemania, en ponencia efectuada en coloquio sobre la reforma a la justicia civil en Chile (en prensa, Abeledo Perrot).

Lent, Friedrich, Obblighi e oneri nel processo civile, en Rivista di Diritto Processuale, 9 (Padova, Cedam, 1954) 1.

Liebman, Enrico Tulio, Manuale di Diritto processuale civile (Milano, Giuffrè, 1957), I.

Losano, Mario, Sistema e struttura nel diritto: Dalle origini alla scuola storica, (Milano, Giuffrè, 2002), I.

Malem Seña, Jorge, El error judicial y la formación de los jueces (Barcelona, Gedisa, 2008).

Marinoni, Luiz - Mitidiero, Daniel, Do projecto do CPC (San Pablo, Dos tribunais, 2010).

MARINONI, Luiz Guilherme, Aproximación critica entre las jurisdicciones del civil lawy del common law y la necesidad de respeto a los precedentes en Brasil, en Constitución $y$ proceso (Lima, Ara, 2009).

Perelman, Chaïm, Ética e direito (Sao Paulo, Martins Fontes, 1999).

PiCARDI, Nicola, Il Giudice naturale, principio fondamentale a livello europeo, en DIDIER Jr. Fredie (ed.), Teoria do processo, panorama doutrinario mundial 2 (2010), pp. 659-669. 
PICARDi, Nicola, La responsabilità del giudice: la storia continua, en Rivista di Diritto Processuale, 1 (Milano, Cedam, 2007).

Picó i Junoy, Joan, El principio de la buena fe procesal (Barcelona, Bosch, 2003).

Picó I Junoy, Joan, Los principios dispositivo y de aportación de parte: significado actual, en Peyrano, Jorge (director), Principios procesales (Buenos Aires, Rubinzal-Culzoni, 2011), I.

Prütting, Hans, Presentación de documentos y dirección del proceso, en PÉRez Ragone, Álvaro - Ortiz Pradillo, Juan Carlos, Código Procesal Civil alemán, Traducción con un Estudio Introductorio al Proceso Civil Alemán Contemporáneo (Montevideo, Konrad Adenauer Stiftung, 2006).

RIcci, Gianfranco, Principi di diritto processuale generale (Torino, Giappicheli), 1998.

ROMERo Seguel, Alejandro, El principio de la buena fe procesal y su desarrollo en la jurisprudencia, a la luz de la doctrina de los actos propios, en Revista Chilena de Derecho, 30 (enero-abril de 2003) 1.

Ross, Alf, On Law and Justice (Clark, New Yersey, 2004).

Sentís Melendo, Santiago, Teoría y práctica del proceso (Buenos Aires, 1959), III.

TARELlo, Giovanni, Storia della cultura giuridica moderna (Mulino, 1976).

TARuffo, Michele, La prova dei fatti guiridici (Giuffrè, Milano, 1992).

Tavolari Oliveros, Raúl, Estudios de Derecho procesal (Valparaíso, Edeval, 1990).

Tavolari, Pía, El abuso en el proceso (Santiago, Ediciones Jurídicas, 2004). 
